\title{
Propriedades Mecânicas e Comportamento a Emissões de Voláteis de Compósitos de Polipropileno/Fibras Curtas de Sílica
}

\author{
Ivani C. dos P. Pizzitola \\ Departamento de Engenharia Metalúrgica e de Materiais da Escola Politécnica, USP \\ Mariana M. Machado \\ Basell Poliolefinas Ltda \\ Hélio Wiebeck \\ Departamento de Engenharia Metalúrgica e de Materiais da Escola Politécnica, USP
}

\begin{abstract}
Resumo: A proteção à saúde humana constitui um dos princípios estabelecidos pelas indústrias automotivas visando ao desenvolvimento e à produção sustentáveis de seus modelos. Desafios residem na redução nos níveis de emissões não só de combustíveis, mas também dos voláteis presentes no interior dos automóveis. A incorporação de fibras curtas de sílica natural amorfa em compósitos de polipropileno foi investigada como uma proposta de desenvolvimento de novos materiais, os quais permitam a redução de peso do veículo e consequente economia de combustível, além de atenderem aos níveis de emissões especificados para componentes internos. Com o objetivo de avaliar o efeito de reforço e a influência do conteúdo de compatibilizante na interface fibra-matriz, amostras com 0 e $20 \%$ em peso de fibra, bem como com variações do teor de PP-g-MAH (0, 1, 2 e 4\% em peso), foram analisadas. Os resultados satisfatórios obtidos para as propriedades de tensão no escoamento, módulo de flexão, alongamento na ruptura, resistência ao impacto Charpy com entalhe e comportamento a emissões sugerem que a concentração ótima do compatibilizante é de $2 \%$, acima da qual as alterações não foram significativas. Conclui-se que fibras curtas de sílica constituem uma alternativa potencial de reforço para materiais empregados em peças automotivas.
\end{abstract}

Palavras-chave: Fibras curtas de sílica, compósitos de polipropileno, comportamento a emissões de voláteis, compatibilizante interfacial.

\section{Mechanical Properties and Volatile Emission Behavior of Short Silica Fibers/Polypropylene Composites}

Abstract: The protection to the human health is one of the most important principles guiding the automotive industries for a sustainable development and production of their cars. The challenges to be faced are not only in reducing fuel consumption but also in decreasing the emission from volatiles in the car interior. The incorporation of natural amorphous short silica fibers in polypropylene composites was investigated as a proposal for creating new materials, aimed at reducing the car weight (with a consequent fuel economy), and meeting the emission requirements for interior components. In order to evaluate the influence from the compatibilizer on the fiber-polymer interface, samples with 0 and 20 wt. (\%) of silica fibers, as well as with varying contents of PP-g-MAH $(0,1,2$ and 4 wt. (\%)), were tested. The satisfactory results obtained for yield stress, flexural modulus, elongation at break, notched Charpy impact strength properties and emission behavior suggest that the optimum compatibilizer content is $2 \mathrm{wt}$. (\%), above which there was no significant change. Therefore, short silica fibers are a potential alternative reinforcement for materials of automotive parts.

Keywords: Silica short fibers, polypropylene composites, volatile emission behavior, interfacial compatibilizers.

\section{Introdução}

As crescentes preocupações sobre o impacto que os automóveis exercem sobre o meio ambiente motivam novos regulamentos ambientais, como o recém proposto pela Comissão Européia, com metas rigorosas para a redução de emissões de dióxido de carbono $\left(\mathrm{CO}_{2}\right)$ para novos automóveis de passageiros. Estas restabelecem desafios para a indústria automobilística quanto ao desenvolvimento de produtos com melhor desempenho, que atendam às perspectivas dos consumidores, inserindo-se no conceito de sustentabilidade, porém sem comprometer a competitividade tão determinante e exigida pelo mercado atual.

Como um dos novos princípios para o desenvolvimento sustentável de produtos, a proteção com a saúde humana leva a atuações para reduzir emissões não só provenientes de combustíveis, mas também de voláteis no interior dos automóveis, os quais se tratam de substâncias presentes nas composições dos materiais empregados nos revestimentos internos, liberadas sob a ação de altas temperaturas. O controle de emissões internas não é uma atividade recente para algumas indústrias automotivas, que a tempo dispõem de normas e especificações adequadas para a avaliação e determinação dos valores permitidos. O "cheirinho do carro novo" é mantido sem comprometimentos à saúde ou ao bem estar dos ocupantes.

A necessidade de redução e minimização das emissões internas estimula o desenvolvimento de métodos sensitivos e instrumentais para a medição de odor. Bledzki et al. ${ }^{[1]}$ descreveram uma técnica sensitiva (olfactometry) para a determinação de odor, visando à redução de emissões indesejáveis para plásticos, nos quais se incluem os empregados pela indústria automobilística. $\mathrm{O}$

Autor para correspondência: Ivani C. dos P. Pizzitola, Departamento de Engenharia Metalúrgica e de Materiais da Escola Politécnica, USP, 
método demonstrou uma detecção com alta reprodutibilidade para medições realizadas com o mesmo grupo de avaliadores, os quais devem ser selecionados a partir de requisitos como sensibilidade olfativa, ausência de resfriados, dentre outros. Guadarrama et $\mathrm{al}^{[2]}$ demonstraram o comportamento funcional de um "nariz eletrônico", ou seja, de um dispositivo formado por conjunto de sensores condutores com base polimérica para a distinção de odores de peças plásticas do interior de veículos. A capacidade de discriminação de odores, para isso, seria melhorada através da utilização dos primeiros coeficientes da Trasnformada de Fourier, com curvas estabelecidas por variações quanto à análise dos componentes principais (PCA).

Não só as características de odor e de emissão de carbono são relevadas pela indústria automobilística para a análise do comportamento a emissões. Limites para emissões de formaldeído e para constituintes condensáveis (fogging) também foram estabelecidos, além da proibição quanto à presença de substâncias simples, classificadas na legislação como cancerígenas.

A investigação quanto às emissões internas, além de evitar exposições a substâncias que oferecem risco à saúde nos primeiros meses após a produção do veículo (os níveis de emissão são reduzidos em função do tempo), é também de extrema importância para a prevenção de eventuais efeitos que possam prejudicar a condução do automóvel pelo motorista (sonolência, desconforto, irritação da garganta, dores de cabeça, náuseas, dentre outros sintomas).

O polipropileno isotático (i-PP) homopolímero é um versátil termoplástico olefínico e possui uma ampla faixa de aplicação em peças internas automotivas. Além do baixo custo, oferece uma combinação de boas propriedades mecânicas, facilidade de moldagem e excelente acabamento superficial ${ }^{[3]}$. Quando reforçado ou carregado, passa a competir em aplicações em que são utilizados plásticos de engenharia mais onerosos, como o $\mathrm{ABS}^{[4,5]}$. Por ser, em média, de 15 a $20 \%$ mais leve que outros polímeros, o polipropileno é uma solução muito atrativa para o cumprimento das novas regulamentações ambientais, através da diminuição do peso do veículo, que por sua vez contribui para a economia de combustível e consequente diminuição de emissões de $\mathrm{CO}_{2}$ para a atmosfera.

Talco e fibras de vidro são os agentes de reforço mais empregados em compósitos de polipropileno que estão presentes ao longo de todo o veículo. As fibras de vidro, apesar das vantagens relacionadas em termos de custo e desempenho mecânico (superior ao do talco), apresentam desvantagens relacionadas à alta densidade $\left(2,56 \mathrm{~g} / \mathrm{cm}^{3}\right)$, ao difícil processamento, à baixa tenacidade obtida pelos compósitos e aos efeitos de anisotropia, como os de empenamento de peças moldadas.

Pesquisas $^{[6-8]}$ citam o efeito de uma fibra natural inorgânica curta $\left(\right.$ Silexil $\left.^{\circledR}\right)$, obtida de recursos minerais em abundância no Brasil, quanto à incorporação como agente de reforço em plásticos. Este tipo de fibra apresenta perto de $100 \%$ em massa de sílica amorfa e densidade de $1,73 \mathrm{~g} / \mathrm{cm}^{3}$, sendo proveniente de minerais denominados espongilitos, que são espículas de sílica originadas de esqueletos de esponjas de água doce e de organismos semelhantes. O material natural é oco, de cor branca, com o aspecto de uma agulha cilíndrica, tubular, tratado superficialmente com aminosilano para melhor acoplamento com a matriz polimérica ${ }^{[6]}$. Em um estudo recente, $\mathrm{Sato}^{[7]}$ analisou a aplicação desta fibra em compósitos híbridos de polipropileno com fibra de madeira e agente de acoplagem, os quais apresentaram boas propriedades mecânicas e redução de peso. As mesmas fibras foram ainda avaliadas por Segatelli ${ }^{[8]}$ como agentes de reforço em compósitos ternários de poliamida 6 , borracha de etileno-propileno-dieno funcionalizada com anidrido maleico (EPDM-g-AM), também com resultados satisfatórios, inclusive evidenciando boa tenacidade sem comprometimento crítico à rigidez.
O objetivo principal deste trabalho foi avaliar a viabilidade do uso da fibra curta de sílica como agente de reforço em compósito de polipropileno homopolímero. Visou-se à aplicação em peças internas automotivas, funcionais ou estruturais, com a vantagem de diminuição da densidade (em função da baixa massa específica das fibras), buscando uma melhor relação de rigidez-tenacidade, bem como atendendo às especificações de uma montadora de veículo quanto ao comportamento a emissões internas. O aumento da afinidade entre as partículas inorgânicas e a matriz foi analisado através da variação de concentrações de polipropileno funcionalizado com anidrido maleico (PP-g-MAH). Os compósitos foram avaliados quanto à morfologia e às propriedades de tensão no escoamento, módulo de flexão, alongamento na ruptura e resistência ao impacto com entalhe. $\mathrm{O}$ efeito dos aditivos e substâncias presentes na formulação de melhor desempenho foi investigado frente ao comportamento a emissões através de método instrumental (cromatografia) e de método sensorial (odor).

\section{Experimental}

\section{Materiais}

Os materiais empregados neste trabalho foram os polipropilenos homopolímeros HP 648S e HP 550K, fornecedor Quattor (índices de fluidez de $40 \mathrm{~g} / 10$ e 3,5 g/10 min, respectivamente, conforme ASTM D- $1238 / 230{ }^{\circ} \mathrm{C} / 2,16 \mathrm{~kg}$ ), e o compatibilizante Bondyram ${ }^{\circledR}$ 1001, fornecedor Polyram, à base de polipropileno homopolímero funcionalizado com anidrido maleico (PP-g-MAH, índice de fluidez de $100 \mathrm{~g} / 10 \mathrm{~min}$ - ISO $1133 / 190{ }^{\circ} \mathrm{C} / 2,16 \mathrm{~kg}$ ) e concentração de MAH de $1 \%$ em massa. As fibras de sílica (Silexil ${ }^{\circledR}$ ), utilizadas como agente de reforço, foram gentilmente fornecidas pela empresa Magnesita. De acordo com as especificações do fabricante, estas apresentam comprimento médio (l) de $200 \mu \mathrm{m}$, diâmetro médio (d) de $10 \mu \mathrm{m}$, razão de aspecto (1/d) de 15 e área superficial de $0,70 \mathrm{~m}^{2} \cdot \mathrm{g}^{-1}$ (BET).

\section{Preparação dos compósitos}

A formulação escolhida foi um compósito com $20 \%$ em peso de fibra. Este teor é de larga aplicação tanto para compósitos com talco, como com fibras de vidro, em peças automotivas. A preparação dos compósitos foi realizada em uma extrusora dupla rosca co-rotacional ZSK25 Super Compounder, da Werner \& Pfleider, com rosca de $25 \mathrm{~mm}$ de diâmetro, com perfil de baixo cisalhamento, relação $\mathrm{L} / \mathrm{D}=44$. A resina e os aditivos foram misturados previamente em um equipamento do tipo Ribbon-blender. A alimentação da pré-mistura e da carga foi efetuada por dosadores gravimétricos Brabender. O resfriamento, para posterior granulação, foi realizado através de acessório tipo "banheira". As misturas foram preparadas com vazão de $10 \mathrm{~kg} / \mathrm{h}$, com velocidade de rotação da rosca de $500 \mathrm{rpm}$ e com um perfil de temperaturas de 200 a $260{ }^{\circ} \mathrm{C}$ ao longo do barril. As amostras foram denominadas:

- PP: polímero puro.

- PP20: polipropileno (PP) com 20\% de fibra de sílica, sem PP-g-MAH.

- PP20-1: PP com 20\% de fibra de sílica, com 1\% de PP-g-MAH.

- PP20-2: PP com 20\% de fibra de sílica, com 2\% de PP-g-MAH.

- PP20-4: PP com 20\% de fibra de sílica, com 4\% de PP-g-MAH.

\section{Injeção dos corpos de prova}

Inicialmente, os materiais foram secados em estufa, com circulação forçada de ar Heraeus BUT 5050 a $120{ }^{\circ} \mathrm{C}$ por 2 horas. A conformação dos corpos de prova foi realizada em uma injetora 
Battenfeld, modelo TM 130/525, com força de fechamento de $1310 \mathrm{kN}$ e com os seguintes parâmetros de processo: perfil de temperatura 185 a $215^{\circ} \mathrm{C}$, molde à $25^{\circ} \mathrm{C}$, tempo de injeção de 20 segundos e pressão de injeção de 20 bar.

\section{Caracterização de propriedades mecânicas $\left(23^{\circ} \mathrm{C}\right)$}

Amostras foram submetidas a ensaios de tração conforme as normas DIN EN ISO 527-1/-2, velocidade de ensaio de $(50 \pm 5) \mathrm{mm} / \mathrm{min}$. O módulo de flexão foi determinado de acordo com os requisitos da norma DIN EN ISO 178, porém com corpos de prova com comprimento de $(50 \pm 1) \mathrm{mm}$, largura de $(6 \pm 0,2) \mathrm{mm}$ e espessura de $4 \mathrm{~mm}$, distância de apoio de $40 \mathrm{~mm}$, raio de apoio de 1,0 até $1,2 \mathrm{~mm}$ e velocidade de ensaio de $(14 \pm 1) \mathrm{mm} / \mathrm{min}$. Os ensaios de resistência ao impacto Charpy com entalhe foram realizados em corpos de prova com as mesmas dimensões dos citados para os ensaios de flexão, segundo a norma DIN EN ISO 179-1, porém com distância de apoio de $40 \mathrm{~mm}$ e tipo de entalhe na forma de "U" de $0,8 \mathrm{~mm}$ de largura (profundidade do entalhe $=1 / 3$ da espessura e com cantos que limitam o fundo do entalhe com raio de arredondamento $<0,1 \mathrm{~mm}$ ) e com pêndulo de $4 \mathrm{~J}$.

\section{Caracterização morfológica}

Corpos de prova de impacto foram fraturados na direção do fluxo de injeção em baixa temperatura, sendo posteriormente analisados quanto à morfologia através dos seguintes microscópios eletrônicos de varredura (MEV):

- JEOL (modelo JSM 7500, tensão de aceleração do feixe $1 \mathrm{keV}$, distância de trabalho de $18 \mathrm{~mm}$, com recobrimento das amostras com carbono); e

- LEO (modelo VP435i, tensão de aceleração do feixe de $20 \mathrm{keV}$, distância de trabalho de $19 \mathrm{~mm}$, com recobrimento das amostras por xputtering).

\section{Caracterização de propriedades específicas - comportamento a emissões}

\section{Emissão total de compósitos orgânicos.}

Cinco amostras, com $(1,000 \pm 0,001) \mathrm{g}$, foram pesadas e colocadas em frascos tipo head-space, hermeticamente fechados e climatizados no emissor de ensaio head-space a $(120 \pm 1){ }^{\circ} \mathrm{C}$ durante 5 horas \pm 5 minutos e, em seguida, analisados com o auxílio do mesmo. O coeficiente reativo foi determinado através da formação do valor médio dentre os sinalizados, resultantes de, no mínimo, cinco medições com frascos vazios. Para a determinação quantitativa da emissão total de carbono foram estabelecidas curvas de calibração utilizando acetona, segundo o método de padrão externo. A avaliação foi efetuada a partir dos dados registrados pelo cromatógrafo para a fase gasosa, sendo obtidos os valores das áreas de pico total, cujo cálculo considerou somente os picos de altura superior ao triplo do ruído da linha básica, bem como com área maior que $10 \%$ da área do pico de acetona na solução de calibração com concentração de 0,5 g.L. $\mathrm{L}^{-1}$. O valor de emissão total $\left(\mathrm{E}_{\mathrm{T}}\right)$ foi obtido a partir da área total de pico $\left(\mathrm{A}_{\mathrm{p}}\right)$, resultante da análise do material de ensaio, do fator de calibração $(\mathrm{k})$ e da área de pico do componente reativo $\left(\mathrm{A}_{\mathrm{R}}\right)$, segundo a equação $E_{T}=\left(A_{P}-A_{R} / k\right) \times 2 \times 0,6204 . \mathrm{O}$ fator 0,6204 representa o índice de massa do carbono presente na acetona.

\section{Teste de odor}

Placas injetadas, referentes a cada um dos compósitos, foram recortadas para a obtenção de $(50 \pm 5) \mathrm{cm}^{3}$ de amostras, as quais foram colocadas em frascos de 1,0 L com tampa e vedações apropriadas. Todos os recipientes tinham sido limpos antes, conforme procedimento adequado, para que ficassem totalmente isentos de qualquer tipo de odor. Os frascos com as amostras, devidamente fechados, foram submetidos à temperatura de $(80 \pm 2){ }^{\circ} \mathrm{C}$ por 2 horas \pm 10 minutos, em estufa, sendo posteriormente resfriados até $(60 \pm 5){ }^{\circ} \mathrm{C}$ em temperatura ambiente e, a seguir, abertos rapidamente para a análise de cada um dos analistas.

\section{Resultados e Discussão}

\section{Propriedades mecânicas}

A Figura 1 ilustra os resultados obtidos para as propriedades de a) tensão no escoamento, b) módulo de flexão, c) alongamento na ruptura; e d) resistência ao impacto Charpy com entalhe, os quais demonstram que as fibras curtas de sílica melhoram a resistência mecânica e a rigidez de compósitos de polipropileno.

As amostras PP20-1, PP20-2, PP20-4, nas quais se adicionou o compatibilizante interfacial PP-g-MAH em diferentes concentrações, apresentaram uma melhor interação fibra-polímero em comparação à amostra PP20, sem a presença deste agente. Em relação ao polímero puro (PP), o compósito PP20-2 obteve um ganho em torno de $21 \%$ em relação à tensão no escoamento e de $86 \%$ para o módulo de flexão. Verifica-se uma ligeira queda para os valores destas propriedades para o compósito PP20-4, com $4 \%$ de $\mathrm{PP}-\mathrm{g}-\mathrm{MAH}$. O alongamento na ruptura é drasticamente menor para os compósitos com fibra de sílica quando comparados ao polímero puro, conforme ilustrado na Figura 1c. A amostra PP demonstra um valor médio de alongamento de $339 \%$, o qual diminui para 7\% para o compósito PP20S-2, de melhor adesão interfacial. Este comportamento é esperado para compósitos reforçados com fibras ou partículas rígidas, as quais restringem a mobilidade da cadeia molecular do polímero ${ }^{[9,10]}$. As formulações com fibras de sílica, com e sem a presença do compatibilizante interfacial, demonstraram, quanto à resistência ao impacto Charpy (com entalhe e em temperatura ambiente), um comportamento muito próximo ou um pouco inferior à do polímero puro, como ilustrado na Figura 1(d), considerando-se o erro inerente ao método.

Há um número significativo de trabalhos publicados ${ }^{[11-15]}$ que tratam a compatibilização interfacial e a sua influência nas propriedades de compósitos de polipropileno reforçados com diversos tipos de cargas e fibras (de vidro e naturais). A sílica é classificada como uma fibra polar, altamente reativa, de caráter hidrofílico e que contém uma grande quantidade de grupos silanóis (Si-OH) em sua superfície. A presença destes grupos induz a uma interação fibra-fibra, que aumenta a tendência das fibras a se aglomerarem na matriz polimérica e, consequentemente, dificulta o processo de dispersão e processamento ${ }^{[1]}$. As fibras de sílica Silexil ${ }^{\circledR}$ são tratadas com o agente 3-aminopropil-trietoxisilano, $\mathrm{H}_{2} \mathrm{~N}-\left(\mathrm{CH}_{2}\right)_{3}$ $\mathrm{Si}\left(\mathrm{OC}_{2} \mathrm{H}_{5}\right)_{3}$, código comercial, Dynasylan ${ }^{\circledR}$ AMEO, fonte Evonik, o qual proporciona um maior grau de "molhabilidade". A adesão interfacial proporcionada por esse tratamento é otimizada pelo uso de polipropileno funcionalizado com anidrido maleico (PP-g-MAH), cujos grupos reativos de ácidos carboxílicos reagem com os grupos básicos amina do silano, formando um copolímero grafitizado de PP-g-silano. Este último atua como um compatibilizante interfacial, melhorando as propriedades do material através de uma melhor transferência de tensões entre fibra e matriz ${ }^{[12,13]}$, como observado para as amostras PP20-1, PP20-2 e PP20-4.

Promover a rigidez sem detrimento à tenacidade é um dos principais desafios durante o desenvolvimento de um compósito reforçado. Os valores de resistência ao impacto com entalhe geralmente refletem a energia absorvida ou dissipada para propagar 


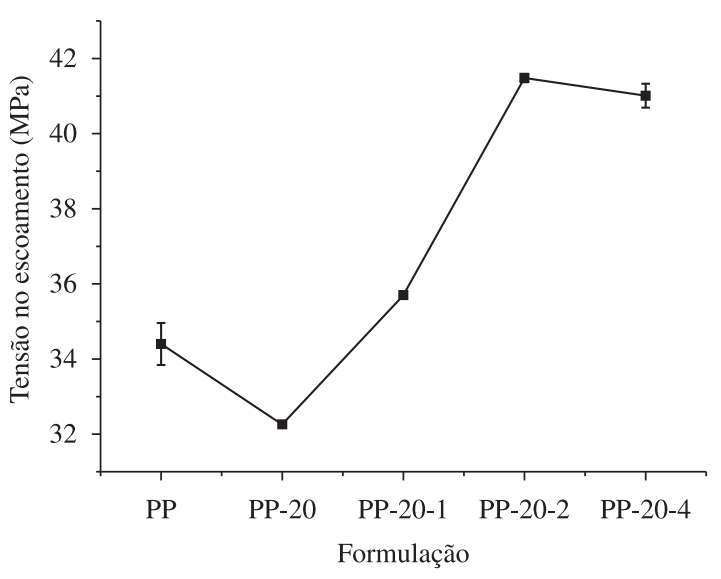

(a)

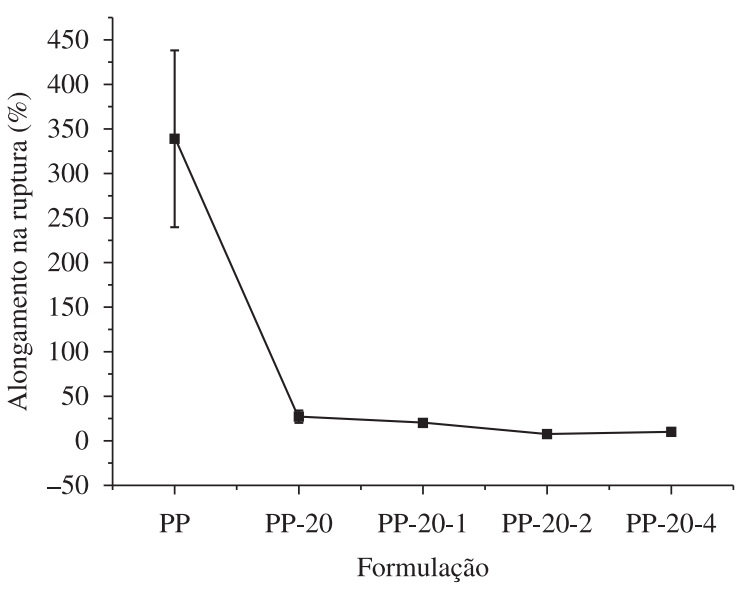

(c)

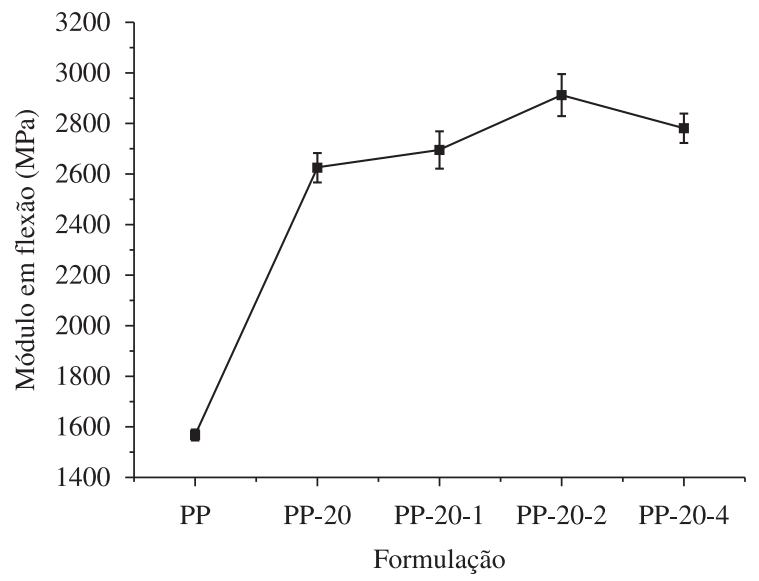

(b)

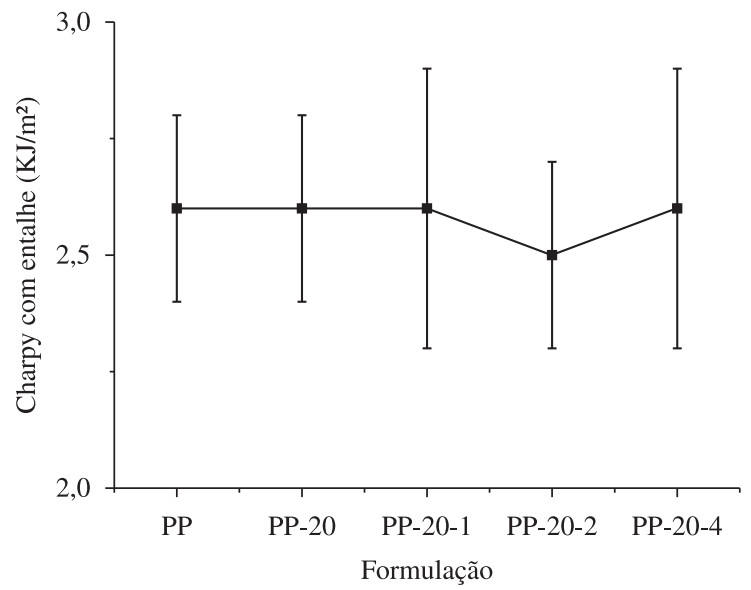

(d)

Figura 1. Variação das propriedades de a) tensão no escoamento; b) módulo de flexão; c) alongamento na ruptura; e d) impacto Charpy com entalhe em função da concentração de compatibilizante interfacial.

uma trinca já existente através da amostra ${ }^{[16]}$, bem como é controlada por sítios de concentração de tensões na região do entalhe. Vários mecanismos de dissipação de energia podem estar envolvidos em uma ruptura por impacto de corpos de prova com entalhe. A carga aplicada pode exceder a resistência da interface fibra-matriz. Fibras podem fraturar se o nível de tensões na região do entalhe for maior que a resistência das mesmas. Para todas as formulações estudadas não houve um comprometimento significativo à resistência ao impacto com entalhe frente à obtida para o polímero puro. A energia absorvida para a propagação das trincas em todos os compósitos foi baixa em função da característica frágil do polipropileno homopolímero, não havendo diferenças significativas de valores mesmo com a melhor interação fibra-matriz e independentemente do mecanismo envolvido no processo.

Através das propriedades investigadas neste trabalho sugere-se que a concentração ótima de PP-g-MAH, a qual corresponde ao ponto de melhor equilíbrio das propriedades de rigidez e tenacidade, é de $2 \%$ em peso. Esta concentração pode corresponder ao ponto de saturação da interface fibra-polímero, conforme observado por Lopes e Sousa ${ }^{[12,13]}$. Eles citam a hipótese de formação de uma camada interfacial mais deformável, constituída de PP-co-siloxano, permitindo uma melhor transferência de tensões entre fibra e matriz, a qual maximiza a relação "resistência - rigidez - tenacidade".

\section{Morfologia (MEV)}

As micrografias eletrônicas de varredura das superfícies das amostras, fraturadas em baixa temperatura, estão ilustradas na Figura 2. A adição do compatibilizante interfacial melhora substancialmente a interface fibra e matriz para os compósitos PP20-2 (2c) e PP20-4 (2d), confirmando os bons resultados obtidos para as propriedades mecânicas. Comparativamente aos compósitos PP20 (2a) e PP20-1 (2b), as amostras PP20-2 e PP20-4 apresentam uma melhor distribuição das fibras e uma menor incidência de pontos de pull out, ou seja, de fibras arrancadas após fratura. O uso do agente compatibilizante propicia uma melhor ancoragem das fibras devido à melhor interação fibra-polímero. Além disso, contribui para uma mistura mais dispersiva e homogênea das fibras, bem como para a preservação do comprimento destas em função da redução da tensão interfacial fibra-polímero ${ }^{[17]}$. Por outro lado, para os compósitos PP20-2 e PP20-4, notam-se algumas fibras desacopladas, com pouca molhabilidade e adesão à matriz. Sugere-se que o tratamento das fibras com o agente aminosilano não foi totalmente efetivo provavelmente devido a um baixo rendimento da reação para a hidrofobização da superfície da fibra de sílica. A orientação das fibras nos compósitos é aleatória, o que diminui o efeito de anisotropia. 


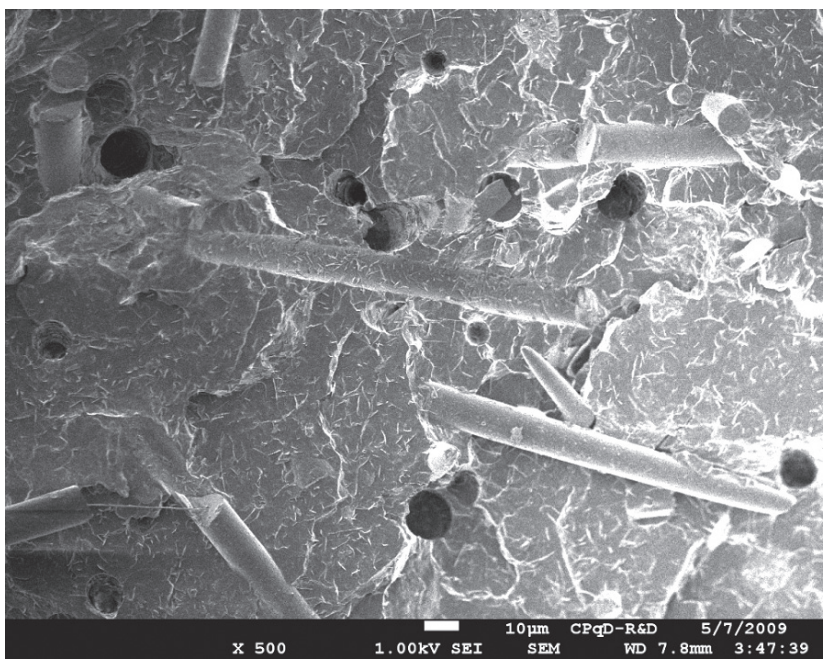

(a)

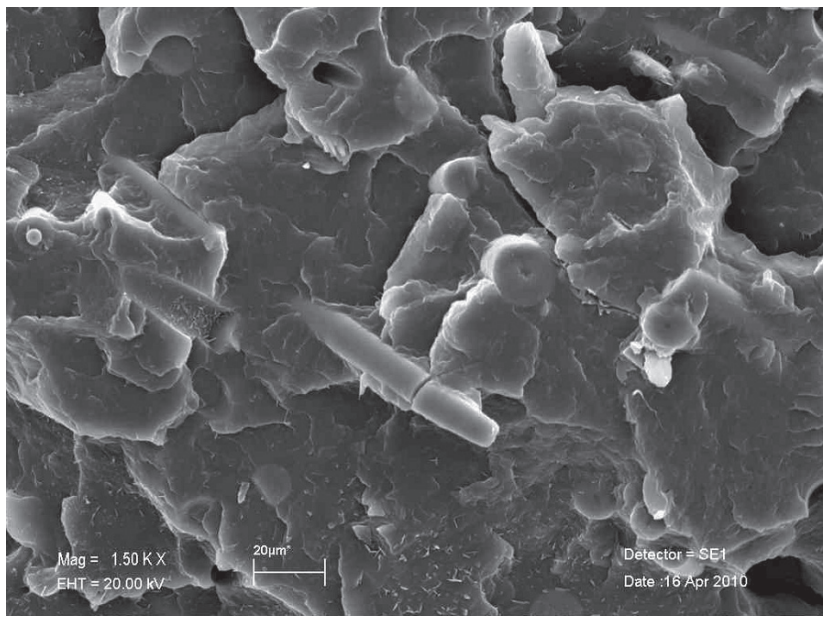

(c)

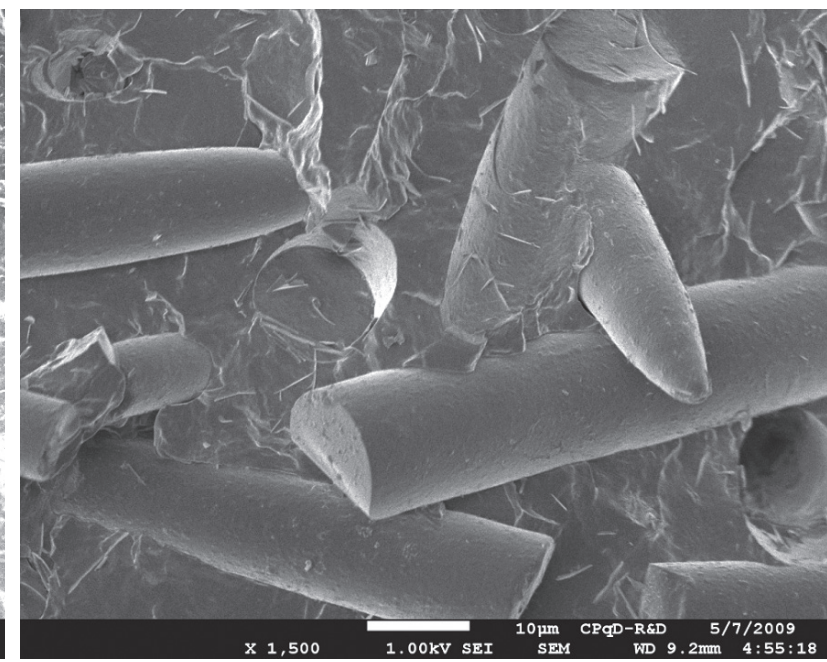

(b)

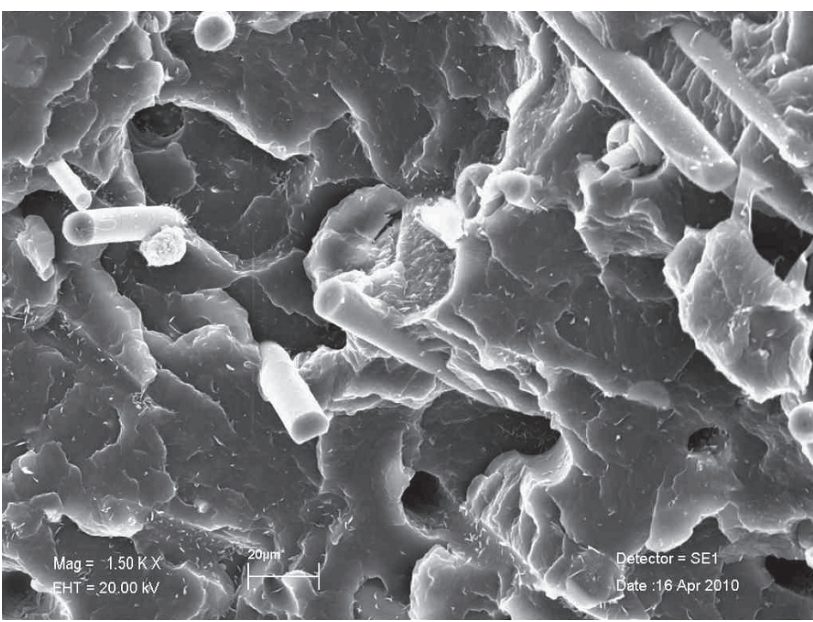

(d)

Figura 2. Micrografias obtidas por microscópio eletrônico de varredura de superfícies de fratura das amostras a) PPP-20; b) PP20-1; c) PP20-2; e d)PP20-4.

Tabela 1. Resultados obtidos para as propriedades de emissão de carbono e de odor.

\begin{tabular}{lcc}
\hline \multicolumn{1}{c}{ Propriedade } & Requisito & Resultado \\
\hline 1. Emissão total de carbono $\left(\mathrm{E}_{\mathrm{T}}\right), \mu \mathrm{gC} \cdot \mathrm{g}^{-1}$ & $\leq 50$ & $1,1 / 1,1 / 1,0 / 1,1 / 0,9$ \\
2. Odor - variante $\mathrm{C}\left(80^{\circ} \mathrm{C}\right)$ & $\leq$ nota 3,5 & $3,5 / 3,5 / 3,5 / 3,5 / 3,5$ \\
\hline
\end{tabular}

\section{Propriedades específicas - comportamento a emissões}

Os resultados obtidos para o compósito PP20-2 e presentes na Tabela 1 demonstram que esta formulação atende aos valores especificados pela indústria automobilística para as propriedades de emissão de carbono total e de odor, sendo que este último foi descrito como "olefínico", ou seja, característico do tipo de polímero avaliado. Não houve percepção de quaisquer substâncias incômodas ou prejudiciais à saúde.

A emissão total de compósitos orgânicos $\left(\mathrm{E}_{\mathrm{T}}\right)$ corresponde à soma de todos os valores resultantes das substâncias, emitidas após uma desagregação cromatográfica em fase gasosa. $\mathrm{O}$ valor do $\mathrm{E}_{\mathrm{T}}$ não deve exceder $50 \mu \mathrm{gC} \cdot \mathrm{g}^{-1}$. A definição deste limite considerou aspectos como volume, características e tipos de materiais presentes no interior do veículo.

$\mathrm{O}$ teste de odor estabelece uma maneira de se determinar a impressão sensorial proporcionada por materiais utilizados no compartimento de passageiros. Os resultados obtidos não são base para determinação quantitativa de substâncias orgânicas por eles emitidas, mas representam uma identificação inicial da presença das mesmas. O odor é avaliado por cinco analistas, os quais atribuem notas em escala de 1 a 6 , sendo nota 1 quanto o odor é imperceptível, e nota 6 quanto é insuportável. O analista também identifica o odor relacionando-o com as substâncias conhecidas e presentes em sua "memória olfativa". Se a nota entre os analistas diferir mais que dois pontos, as avaliações deverão ser repetidas. A nota final será a média aritmética das cinco determinações. A condição de ensaio avaliada neste trabalho é classificada como Variante C, e é correlacionada com as condições de aplicação prováveis para os compósitos em estudo. A nota especificada deve ser menor ou igual a 3,5. O valor corresponde a um odor perceptível, porem não ofensivo ou irritante.

A escolha dos tipos e teores de resinas e dos aditivos (antioxidantes primários e secundários, compatibilizantes, agentes dispersantes e facilitadores de fluxo) para as formulações desenvolvidas neste 
trabalho teve como objetivo inicial a obtenção de compósitos com um bom balanço de propriedades. Por outro lado, os satisfatórios resultados de emissões e de odor nos permite verificar que o sistema de estabilização escolhido mostrou-se eficiente quanto à inibição dos mecanismos de degradação termo-oxidativa. Além disso, as substâncias utilizadas não contribuíram para a percepção de odores fortes e desagradáveis. Os baixos níveis de emissões de carbono também são valores indicativos de condições adequadas de processamento, apesar das condições adversas proporcionada pela rigidez e pela abrasividade das fibras de sílica.

\section{Conclusão}

Os resultados obtidos neste trabalho indicam que as fibras de sílica Silexil ${ }^{\circledast}$ podem ser utilizadas como uma alternativa de reforço para compósitos de polipropileno empregados na indústria automotiva, com a vantagem da redução de peso, em aplicações específicas.

A presença do compatibilizante interfacial PP-g-MAH proporcionou uma melhor adesão e transferência de tensões do polímero para as fibras. Em termos comparativos, o módulo de flexão obtido para esse compósito foi, aproximadamente, $86 \%$, superior à do compósito puro. Através das propriedades investigadas sugere-se que a concentração ótima do compatibilizante interfacial, a qual corresponde ao ponto de melhor equilíbrio dos requisitos de rigidez e tenacidade, é de $2 \%$ em peso. Os valores satisfatórios obtidos para o comportamento frente a emissões voláteis mostram que o compósito PP20-2 pode ser aplicado em peças do interior do veículo, sem prejuízo à saúde ou ao bem estar dos ocupantes.

\section{Agradecimentos}

Os autores agradecem à LyondellBasell e à Volkswagen do Brasil (Centro Tecnológico de Materiais) pela contribuição na preparação dos compósitos e na realização dos ensaios.

\section{Referências Bibliográficas}

1. Bledzki, A. K.; Kessler, A. \& Lieser, J. - Polym. Test., 18, p.63 (1999). http://dx.doi.org/10.1016/S0142-9418(98)00008-7

2. Guadarrama, A; Rodriguez-Méndez, M. L. \& de Saja, J. A, - Anal. Chim. Acta, 455, p.41 (2002). http://dx.doi.org/10.1016/S00032670(01)01584-7

3. Ota, W. N. - "Análise de Compósitos de Polipropileno e Fibras de Vidro Utilizados pela Indústria Automotiva Nacional”, Dissertação de Mestrado, Universidade Federal do Paraná, Brasil (2004).
4. Karger Carvalho, G. M. X.; Mansur, H. S.; Vasconcelos, W. L. \& Oréfice, R. L., - Polímeros, 17, p.99 (2007).

5. Ishizaki, M. H. \& Visconte, L. L. Y. - Polímeros, 16, p.183 (2006). http://dx.doi.org/10.1590/S0104-14282006000300006

6. Saliba, C. C.; Oréfice, R. L.; Carneiro, J. R. G.; Duarte, A. K.; Schneider, W. T. \& Fernandes, M. R. F. - Polym. Test., 24, p.820 (2005).

7. Sato, A. K. - "Desenvolvimento e Caracterização de um Compósito Híbrido de Polipropileno Homopolímero e Micro Fibra de Sílica Amorfa e Fibra de Madeira, Utilizando Agente de Acoplagem", Dissertação de Mestrado, Universidade Estadual de Campinas, Brasil (2008)

8. Segatelli, M. G. - "Avaliação das Propriedades Mecânicas e da Morfologia de Compósitos Ternários de Poliamida 6, Borracha de Etileno-Propileno-Dieno e Fibras Curta de Sílica", Dissertação de Mestrado, Universidade Estadual de Campinas, Brasil (2005).

9. Premalal, H. G. B.; Ismail, H. \& Baharin, A. - Polym. Test., 21, p.837 (2002).

10. Spinancé, M. A. S; Fermoseli, K. K. G.; De Paoli, M. A. - J. Appl. Polym. Sci., 112, p.3689 (2008).

11. Osman, H; Ismail, H. \& Mariatti, M. - J. Reinf. Plast. Comp., 29, p.61 (2010).

12. Lopes, P. E. \& Sousa, J. A. - Polímeros, 9, p.100 (1999). http://dx.doi. org/10.1590/S0104-14281999000400017

13. Lopes, P. E. \& Sousa, J. A. - "Influence of PP-g-MAH Compatibilizer Characteristics on Interphase and Mechanical Properties of Glass Fiber Reinforced Polypropylene Composites", in: $18^{\text {th }}$ Polymer Processing Society Annual Meeting, p.9, Guimarães - Portugal, jun (2002).

14. Correa, C. A.; Fonseca, C. N. P. \& Neves, S. - Polímeros, 13, p.154 (2003). http://dx.doi.org/10.1590/S0104-14282003000300005

15. Cruz, M. C. A. - "Correlações entre Propriedades DinâmicoMecânicas e Durabilidade sob Fadiga Mecânica em Compósitos de Polipropileno/Polipropileno Maleificado / Fibra de Vidro", Dissertação de Mestrado, Universidade Federal de São Carlos, Brasil (2006).

16. Ansari M. N. M. \& Ismail, H. - Journal of Reinforced Plastics and Composites, 28, p.3049 (2009). http://dx.doi. org/10.1177/0731684408095197

17. Lopes, P. E. \& Sousa, J. A. - Polímeros, 9, p.85 (1999). http://dx.doi. org/10.1590/S0104-14281999000400017

Enviado: $12 / 06 / 10$

Reenviado: $25 / 10 / 10$

Aceito: $14 / 01 / 11$

DOI: $10.1590 / \mathrm{S} 0104-14282011005000037$ 